\title{
Density functional theory studies of $\beta$-substituent effect on conformational preference and anion binding ability of calix[4]pyrroles
}

\author{
Di-Fei Wang ${ }^{\mathrm{a}, \S}$ and Yundong $\mathrm{Wu}^{\mathrm{b}, \mathrm{c}^{*}}$ \\ ${ }^{a}$ Department of Chemistry, The Hong Kong University of Science \& Technology, Clear Water \\ Bay, Kowloon, Hong Kong, China, and ${ }^{b}$ State Key Laboratory of Molecular Dynamics and \\ Stable Species, College of Chemistry, Peking University, Beijing, China \\ E-mail:chydwu@ust.hk
}

Dedicated to Professor Chengye Yuan on his $80^{\text {th }}$ anniversary

(received 31 May 04; accepted 03 Sep 04; published on the web 19 Sep 04)

\begin{abstract}
The conformational features and anion-binding properties of a series of $\beta$-octasubstituted calix[4]pyrroles have been investigated by the BLYP method of density functional theory with the $6-31+\mathrm{G}^{* *}$ basis set both in the gas phase and in $\mathrm{CH}_{2} \mathrm{Cl}_{2}$ solution. The calculations demonstrated that adjusting the electronic properties of $\beta$-substituents on the pyrrole rings do change the anion-binding ability of calix[4]pyrroles. With the BLYP/6-31+G** method in $\mathrm{CH}_{2} \mathrm{Cl}_{2}$ solution, the relative binding energies follow the order of electron withdrawing abilities of the substituents, i.e. $\mathrm{CN}(18 \mathrm{kcal} / \mathrm{mol})>>\mathrm{Cl}(7 \mathrm{kcal} / \mathrm{mol})>\mathrm{Br}(4 \mathrm{kcal} / \mathrm{mol})>\mathrm{H}(0 \mathrm{kcal} / \mathrm{mol})$. Calculations also indicate that the energy difference between the most stable 1,3-alternate conformation and the least stable cone-conformation that is for anion-binding is increased by electron-withdrawing $\beta$-substituents $\mathrm{CN}, \mathrm{Cl}$, and $\mathrm{Br}$. Further analysis on dipyrromethane models reveals that the destabilization of the cone-conformation is mainly caused by electrostatic interactions between the $\beta$-substituents on the adjacent pyrrole rings. Our results thus provide useful information for designing stronger and more efficient calix[4]pyrrole-based anion binding receptors.
\end{abstract}

Keywords: DFT calculation, calix[4]pyrrole, substituent effect, anion binding

\section{Introduction}

Anion binding is a very important process in biological events, as evidenced by the fact that the substrates of many characterized enzymes are anionic in nature. ${ }^{1}$ For example, about $70 \%$ of

\footnotetext{
$\S$ Present address: Department of Chemistry and Biochemistry, University of Notre Dame, Notre Dame IN 46556, USA
} 
enzyme substrates and cofactors are anions, mostly phosphates; even for simple chloride anion, it is the major extracellular species and linked intimately to cystic fibrosis. Due to the importance of anion recognition, there has been a boom in the design and synthesis of receptors for specific anion binding in the past decade. ${ }^{2,3}$ Calix[4]pyrrole 1, one of the easy-to-make calix[4]arene-like hosts, has been found by Sessler's group to have the ability to bind anions, such as $\mathrm{F}^{-}, \mathrm{Cl}^{-}$and $\mathrm{PO}_{3}{ }^{2-}$, and neutral guests. ${ }^{3}$

Although there have been many theoretical studies on the conformational features of calix[4]arenes, ${ }^{4,5}$ there are only a few theoretical investigations of calix[4]pyrrole, ${ }^{6,7,8 a}$ and other

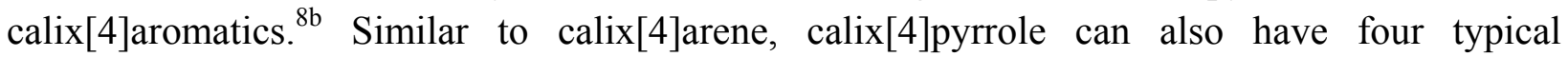
conformations. However, it does not adopt the cone conformation either in the solid state or in $\mathrm{CH}_{2} \mathrm{Cl}_{2}$ solution. Instead, the 1,3-alternate conformer is the most stable one. Our recent density functional theory (DFT) study and the molecular mechanics calculations with OPLS force field by Jorgensen's group both reproduced this experimental observation. ${ }^{6,8 a}$ The stability sequence of calix[4]pyrrole 1 is predicted to be 1,3-alternate $>$ partial cone $>1,2$-alternate $>$ cone. The electrostatic repulsions between the adjacent pyrrole-pyrrole ring pairs destabilize the cone conformation severely while they are almost absent in the 1,3-alternate conformation. In agreement with the experimental results, it was found that calix[4]pyrrole 1 can bind anions tightly. Without any substituent, theoretically, its binding energy is about $20 \mathrm{kcal} / \mathrm{mol}$ for fluoro anion in $\mathrm{CH}_{2} \mathrm{Cl}_{2}$ solution. Even for chloro anion, its binding strength still remains $10 \mathrm{kcal} / \mathrm{mol}$ in energy. With eight methyl groups at the meso carbon position of calix[4]pyrrole 1, our calculations show that the methyl groups would reduce the anion-binding ability of calix[4]pyrrole. Quantitatively, the eight meso-methyl substituents reduce the anion binding energy by about $4.4 \mathrm{kcal} / \mathrm{mol}$ in $\mathrm{CH}_{2} \mathrm{Cl}_{2}$ solution. ${ }^{8 \mathrm{a}}$

How can we design an anion receptor that can bind anions even more tightly? One simple way to strengthen the anion-binding is to increase the binding force, i.e. hydrogen bond strength between the host and anion. Modification of the hydrogen bond acceptor (host part) is apparently a possible approach. In fact, at the beginning of exploring the anion binding properties of calix[4]pyrrole, Sessler and his coworkers have realized that modification of the C-rim of calix[4]pyrrole may tune its binding ability. ${ }^{3}$ Through NMR titration measurement in $\mathrm{CD}_{2} \mathrm{Cl}_{2}$ at room temperature, the bromine substituted calix[4]pyrrole $\mathbf{3}$ demonstrated a stronger binding constant than its parent structure $\mathbf{2}$ with various anions as shown in Figure 1. The fluoro anionbinding constant of $\mathbf{3}$ is roughly 2 -fold larger than that of the parent structure $\mathbf{2}$. As expected, host molecule 4 has the weaker anion binding strength with fluoro, chloro and bromo anions. Its fluoro anion binding constant is only about $170 \mathrm{M}^{-1}$, almost 100 -fold less than that of compound 2. For the binding of chloro and bromo anions, the substituent effects become larger. The binding constants of $\mathbf{3}$ are about 10-fold and 65-fold larger than those of $\mathbf{2}$ for the binding of chloro and bromo anions, respectively. In contrast to $\mathbf{3}$, the binding ability of $\mathbf{4}$ decreases significantly in such cases. 


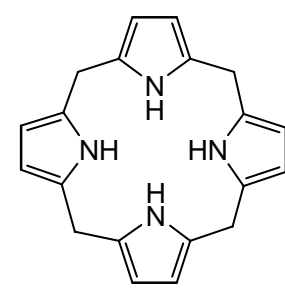

1

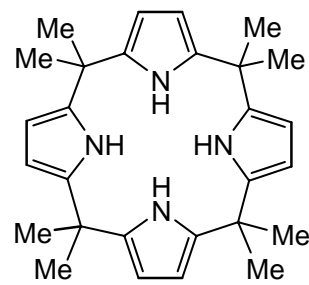

2

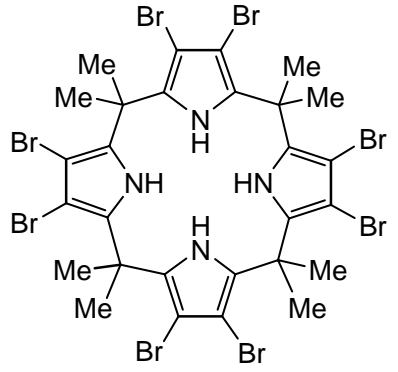

3

$\beta$-octabromo-mesooctamethylcalix[4]pyrrole

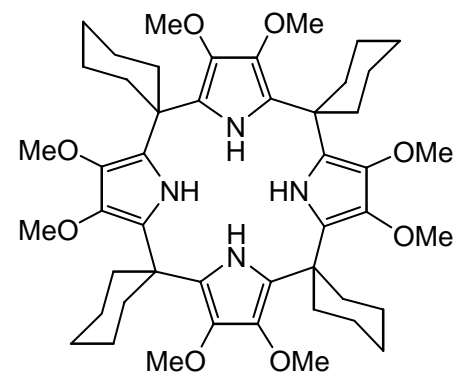

4

$\beta$-octamethoxy-mesotetraspirocyclohexylcalix[4]pyrrole

parent calix[4]pyrrole

meso-octamethyl calix[4]pyrrole

Binding Constant $\left(\mathrm{M}^{-1}\right)^{\mathrm{a}}$

\begin{tabular}{cccc}
\cline { 2 - 4 } Anions & $\mathbf{2}$ & $\mathbf{3}$ & $\mathbf{4}$ \\
\hline Fluoride & $17170( \pm 900)$ & $27000( \pm 4000)$ & $170( \pm 20)$ \\
Chloride & $350( \pm 5.5)$ & $4300( \pm 600)$ & $<10$ \\
Bromide & $10( \pm 0.5)$ & $650( \pm 40)$ & - \\
\hline
\end{tabular}

${ }^{\mathrm{a}}$ Binding constants for hosts $\mathbf{2 , 3}$ and $\mathbf{4}$ with anionic substrates in $\mathrm{CD}_{2} \mathrm{Cl}_{2}$ at $298 \mathrm{~K}$. Data from ref 3.

Figure 1. Structures of parent calix[4]pyrrole $\mathbf{1}$ and its substituted analogues 2-4 which have been studied experimentally by Sessler et $a{ }^{3}{ }^{3}$

We have carried out a theoretical study to understand the origin of the $\beta$-substituents of pyrrole ring on the anion-binding property of calix[4]pyrrole. Our calculations used model systems shown in Figure 2. By studying the effects of $\beta$-substituents on the anion-binding by pyrrole itself (8-14) and calix[4]pyrroles (5-7), and analysing the influence of $\beta$-substituents on the energetic preference of 1,3-alternate and cone conformations of calix[4]pyrroles, we are able to obtain information for the design of stronger calix[4]pyrrole-based anion-binding receptors.

\section{Computational methods and details}

All calculations used the Gaussian 94 program. ${ }^{9}$ In general, structures were optimized by the PM3 semiempirical method and density functional method (BLYP, Beck 88 exchange and LeeYang-Parr correlation) with the $3-21 \mathrm{G}$ basis set first. ${ }^{10}$ For a proper description of anion, it is necessary to supplement the basis set with a set of diffuse s- and p-functions. ${ }^{11}$ So single point energies in the gas phase and solution were evaluated with the BLYP/6-31+G** based on the $\mathrm{BLYP} / 3-21 \mathrm{G}$ geometries. To investigate the solvent effect on the conformational preference and anion-binding energies, the self-consistent isodensity polarization continuum model, SCIPCM, was used. ${ }^{12}$ The isodensity value and dielectric constant were 0.0004 and 8.0 respectively to model $\mathrm{CH}_{2} \mathrm{Cl}_{2}$ solvent. 
In $\beta$-disubstituted pyrrole models, all the structures were optimized at the BLYP/3-21G level first, then further optimized with the $6-31+\mathrm{G}^{* *}$ basis set in order to investigate the pyrrole-anion interaction energy properly. The SCIPCM model was also employed to evaluate the solvent effect same as we described above.

\section{$\beta$-octasubstituted-calix[4]pyrroles}

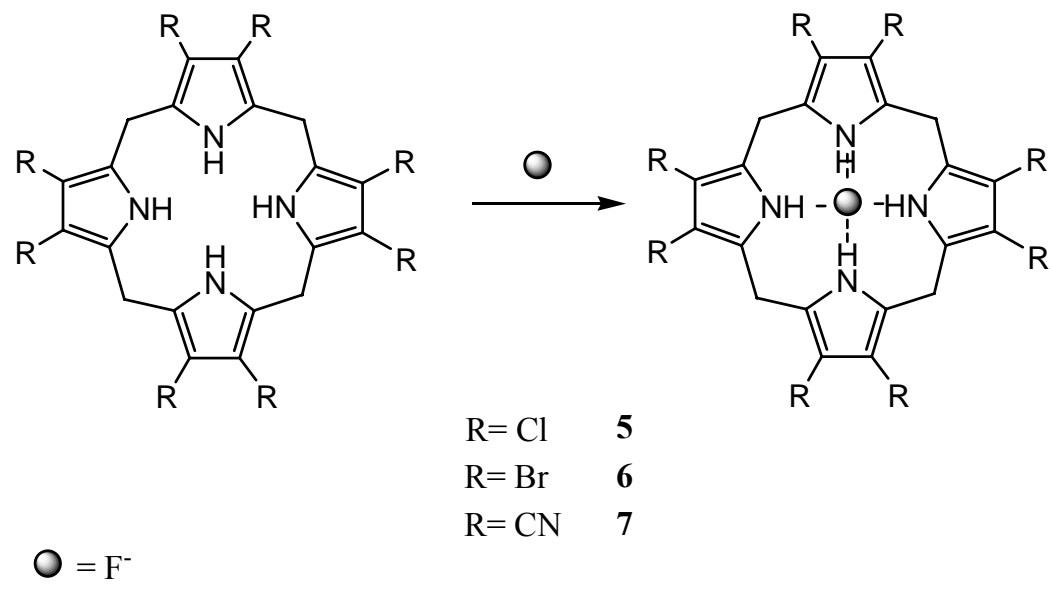

\section{Disubstituted pyrrole models}

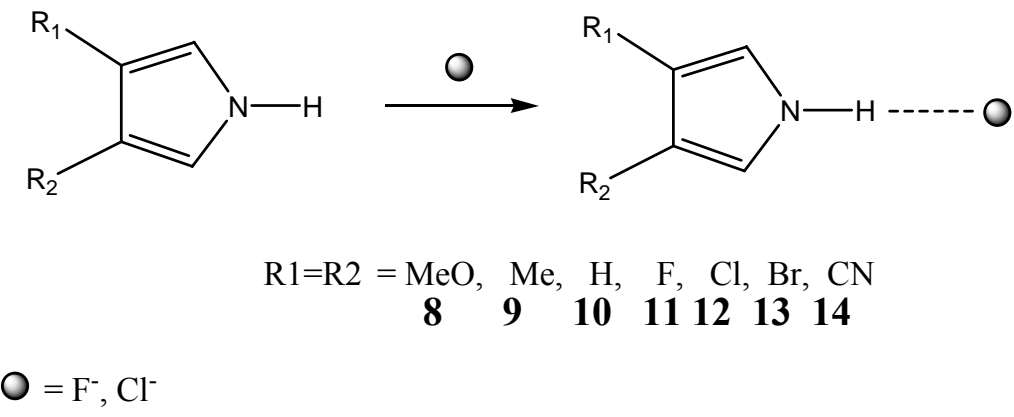

Figure 2. Systems studied in this work.

\section{Results and Discussion}

Figures 3-4 give the calculated geometries of compounds 5-14. The calculated anion binding energies of these structures are collected in Table 1. In order to describe the molecular shape, we adopted the mean plane method that we used in our previous work. ${ }^{8}$ 


\section{I. $\beta$-Disubstituted pyrrole-anion models}

We first used the $\beta$-disubstituted pyrrole-anion models to examine the direct influence of the various substituents on the $\mathrm{N}-\mathrm{H}---\mathrm{Y}^{-}(\mathrm{Y}=\mathrm{F}, \mathrm{Cl})$ hydrogen bond, which is the crucial component in the anion binding process. The calculated structures 8-14 and their fluoro and chloro anion binding complexes 8-F-14-F ${ }^{-}$and $\mathbf{8}-\mathbf{C l}^{-} \mathbf{- 1 4}-\mathbf{C l}^{-}$are given in Figure 3.

In the anion-free pyrroles, the bond length of $\mathrm{N}-\mathrm{H}$ is about 1.01-1.02 $\AA$ at the BLYP/6$31+\mathrm{G}^{* *}$ level in the gas phase. When fluoro anion is involved, the $\mathrm{N}-\mathrm{H}$ bond is elongated to 1.24-1.46 $\AA$ varying in different substituted structures. The stronger electron-withdrawing group normally elongates the $\mathrm{N}-\mathrm{H}$ bond more while the $\mathrm{H}-\mathrm{F}$ bond is significantly shortened. This implies that the basicity of $\mathrm{F}^{-}$is stronger than those of the pyrrole anions in the gas phase. Therefore, the $\mathrm{H}(\mathrm{N})$ atom is fully abstracted from pyrrole by fluoro anion in some cases. Similar

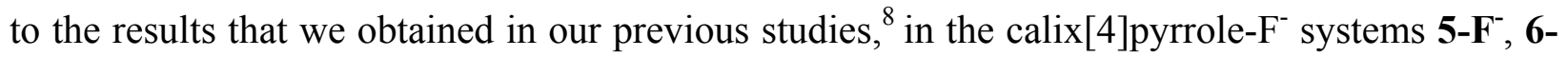

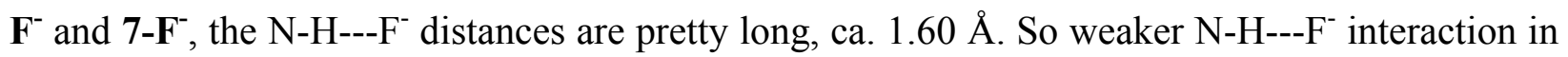
$\mathbf{5}-\mathbf{F}^{-}, \mathbf{6}-\mathbf{F}^{-}$and $\mathbf{7 - \mathbf { F } ^ { - }}$ anion complexes should be predicted by comparing with that in the model we described here. For chloro anion complexes, the situations are very different. All complexes have slightly longer N-H bond lengths, ca. 1.06-1.10 A, by comparing with the N-H bond lengths in their anion-free structures. In contrast, the $\mathrm{H}---\mathrm{Cl}^{-}$distances (1.89-2.09 $\AA$ ) are much longer than those in fluoro anion complexes. So the $\mathrm{N}-\mathrm{H}---\mathrm{Cl}^{-}$interaction would be much weaker than that in the fluoro anion complex.

Indeed, the evaluations of anion binding energies show that the introduction of an electronwithdrawing group does significantly enhance the anion-binding energy of pyrrole. In the gas phase, the complexation energies are very high at different levels, especially for fluoro anion complexes. At the BLYP/6-31+G** level, they are about 40.4, 38.9 and $38.6 \mathrm{kcal} / \mathrm{mol}$ for 8-F', $\mathbf{9}-\mathbf{F}^{-}$and $\mathbf{1 0}-\mathbf{F}^{-}$. The larger binding energy of $\mathbf{8}-\mathbf{F}^{-}$than the parent $\mathbf{1 0}-\mathbf{F}^{-}$is attributed to the weak electron-withdrawing property of methoxyl group in the gas phase. The fluoride binding energies in $\mathbf{1 1}-\mathbf{F}^{-}, \mathbf{1 2}-\mathbf{F}^{-}$and $\mathbf{1 3 - \mathbf { F } ^ { - }}$ are similar, and they are about $10 \mathrm{kcal} / \mathrm{mol}$ larger than that in the parent 10-F'. For 14-F', the binding energy $E_{F^{-}}$is extremely high, it is about $30 \mathrm{kcal} / \mathrm{mol}$ higher than for $\mathbf{1 0 - \mathbf { F } ^ { - }}$. In $\mathrm{CH}_{2} \mathrm{Cl}_{2}$ solution, all the binding energies reduce drastically. However, the trend of binding ability remains. Thus, the binding energy of $\mathbf{1 4 - \mathbf { F } ^ { - }}$ is still about $14 \mathrm{kcal} / \mathrm{mol}$ higher than that of the parent model 10-F'.

For the chloro anion binding cases, the bindings are significantly weaker than the fluoro

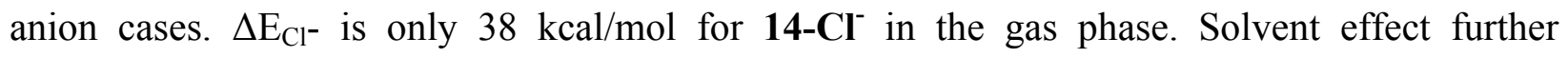

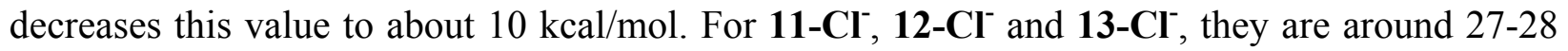
$\mathrm{kcal} / \mathrm{mol}$ in the gas phase, and 6-7 kcal/mol in $\mathrm{CH}_{2} \mathrm{Cl}_{2}$ solution. Electron-donating groups $\mathrm{MeO}$ and $\mathrm{Me}$ do not influence the binding energy very much. Their binding energies are only about 3.6 and $4.2 \mathrm{kcal} / \mathrm{mol}$, respectively. 
Disubstituted pyrroles

Fluoride anion complexes

Chloride anion complexes
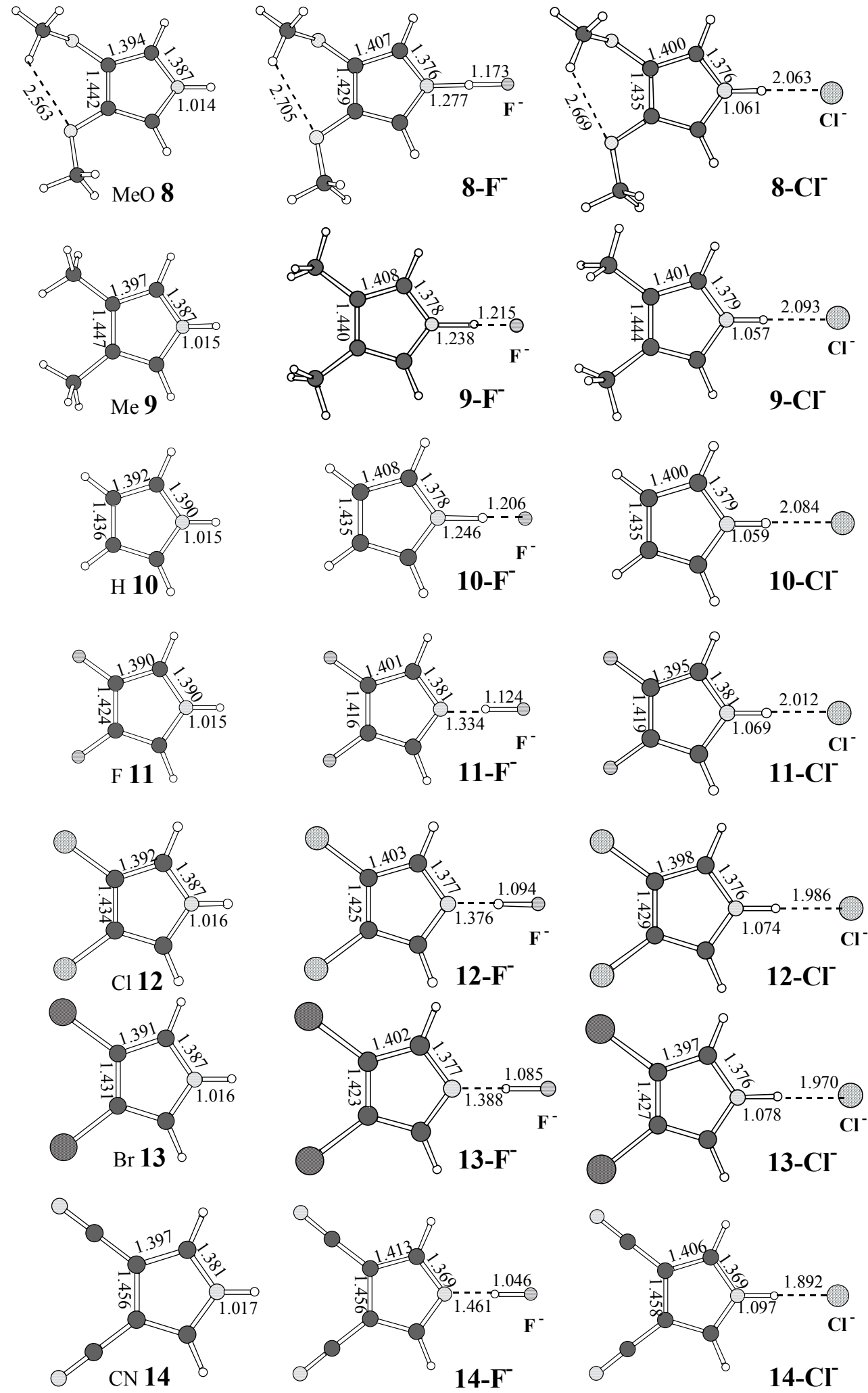

Figure 3. BLYP/6-31+G** calculated disubstituted pyrroles and their $\mathrm{F}^{-}$and $\mathrm{Cl}^{-}$complexes. 


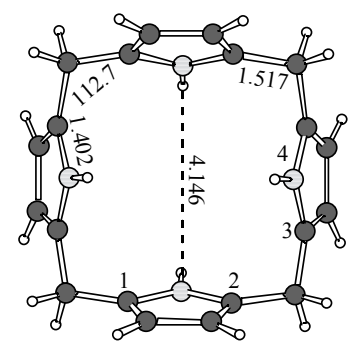

$1 \mathrm{a}$

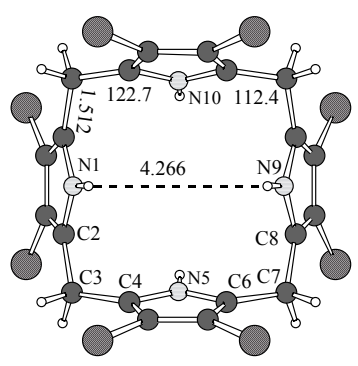

$5 a$

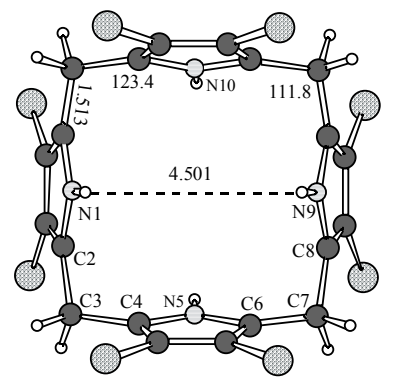

$6 a$

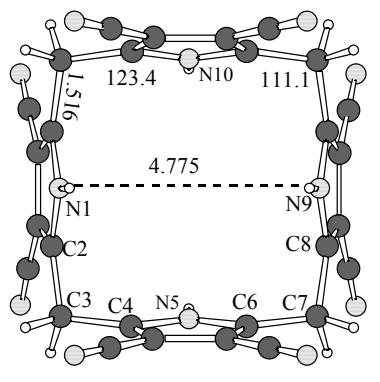

$7 a$

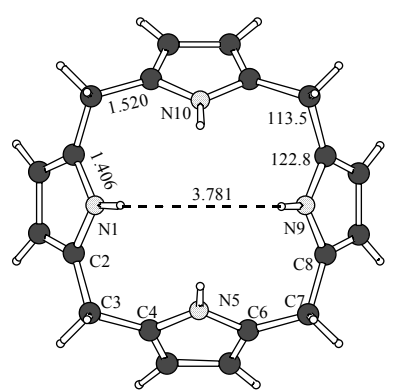

$1 \mathrm{~b}$

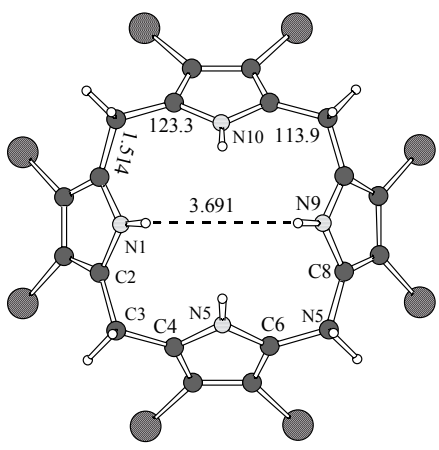

$5 b$

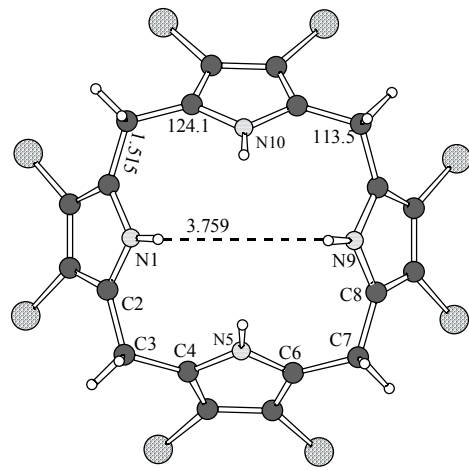

6b

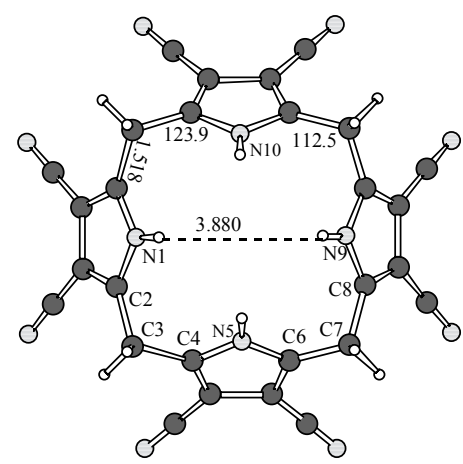

$7 b$

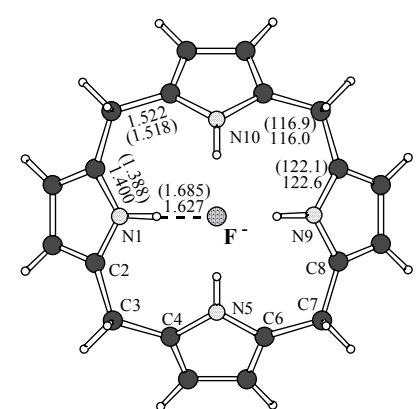

$1-\mathrm{F}^{-}$

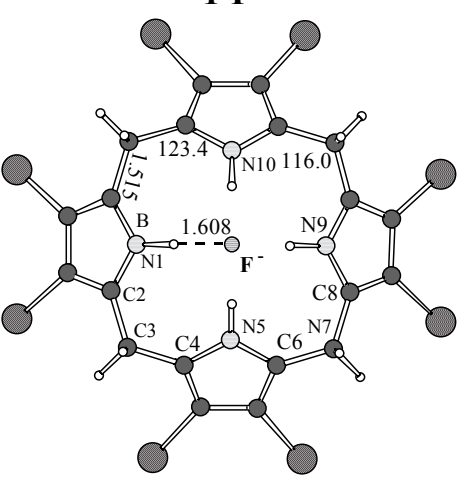

5-F

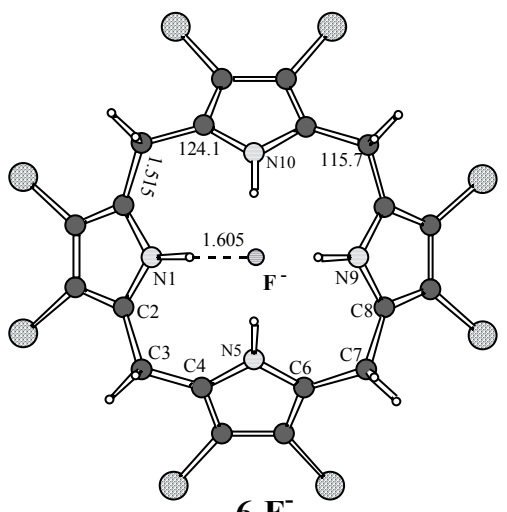

6-F

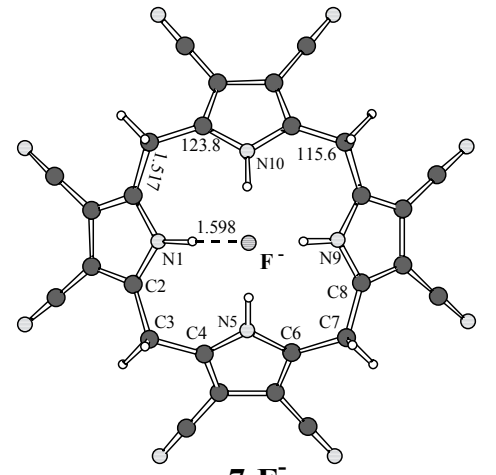

7-F

Figure 4. Calculated structures of 1,3-alternate and cone conformations of parent calix[4]pyrrole 1, $\beta$-octachloro-calix[4]pyrrole 5, $\beta$-octabromo-calix[4]pyrrole 6, $\beta$-octacyano-calix[4]pyrrole 7 and their fluoro anion binding complexes. 
It appears that both $\sigma$ and $\pi$ effects of the substituents affect the anion binding energy. Methoxy group is a strong $\pi$ donor and a weak $\sigma$ acceptor. While the $\pi$-donating factor decreases the binding energy, the $\sigma$-accepting factor increases the binding energy. As a result, the methoxy group has little effect on the binding energy. Fluoro-, chloro-, and bromo- groups are stronger $\sigma-$ acceptors, and they overall behave as electron-acceptors. Therefore, they all increase the binding energy to similar extents. Cyano group is a strong electron-acceptor, and it can significantly increase the binding energy.

In comparison with the experimental results, the simple substituted pyrrole-anion models do not represent the calix[4]pyrrole-anion complexes well. This indicates that the anion binding energy of the calix[4]pyrroles is not affected by the acidity of substituted pyrrole along. Other factors may also play important roles.

Table 1. Calculated anion-binding energies $\left(\Delta \mathrm{E}_{\mathrm{X}^{-}}, \mathrm{X}^{-}=\mathrm{F}^{-}, \mathrm{Cl}^{-}\right)$in $\mathrm{kcal} / \mathrm{mol}$ of $\beta$-disubstituted pyrroles

\begin{tabular}{|c|c|c|c|c|c|}
\hline & $\begin{array}{c}\text { BLYP } \\
6-31+G^{* *}\end{array}$ & $\begin{array}{c}\text { BLYP } \\
6-31+\mathrm{G}^{* *}(\text { sol. })\end{array}$ & & $\begin{array}{c}\text { BLYP } \\
6-31+\mathrm{G}^{* *}\end{array}$ & $\begin{array}{c}\text { BLYP } \\
6-31+\mathrm{G}^{* *} \text { (sol.) }\end{array}$ \\
\hline $8-F^{-}$ & -40.4 & -13.3 & $8-\mathrm{Cl}^{-}$ & -19.8 & -3.6 \\
\hline $9-F^{-}$ & -38.9 & -13.1 & $9-\mathrm{Cl}^{-}$ & -19.6 & -4.2 \\
\hline $10-F^{-}$ & -38.6 & -13.4 & $10-\mathrm{Cl}^{-}$ & -19.1 & -3.7 \\
\hline $11-F^{-}$ & -48.4 & -18.7 & $11-\mathrm{Cl}^{-}$ & -25.5 & -6.6 \\
\hline $12-F^{-}$ & -51.6 & -19.0 & $12-\mathrm{Cl}^{-}$ & -27.0 & -6.3 \\
\hline $13-F^{-}$ & -52.9 & -19.2 & $13-\mathrm{Cl}^{-}$ & -27.9 & -6.5 \\
\hline $14-F^{-}$ & -68.3 & -27.5 & $14-\mathrm{Cl}^{-}$ & -38.2 & -10.1 \\
\hline
\end{tabular}

\section{II. $\beta$-Substituent effects on anion-binding abilities of calix[4]pyrrole}

\section{A. $\beta$-Substituent effects on different conformations of calix[4]pyrrole: 1,3-alternate v.s. cone}

Three $\beta$-octasubstituted calix[4]pyrroles 5, 6, and 7 were calculated to estimate their anion binding energies. Octamethoxycalix[4]pyrrole was not calculated due to large number of possible conformations. As can be seen later, the effect of the methoxy group can be understood based on the calculations for 5-7.

As mentioned in our previous studies, ${ }^{8}$ two typical conformations of calix[4]pyrrole are involved in the anion binding process. One is the global minimum conformation, the 1,3alternate conformation. The other is the cone conformation that is the structure for anion binding. Thus, only these two conformations were considered in this study. The calculated structures of 1,3-alternate and cone conformations of $\beta$-octachloro-calix[4]pyrrole $\mathbf{5}, \beta$-octabromocalix[4]pyrrole 6, $\beta$-octacyano-calix[4]pyrrole 7 and their fluoro anion binding complexes are shown in Figure 4. 
Comparing with our previous results on the 1,3-alternate and cone conformations $\mathbf{1 a}$ and $\mathbf{1 b}$ of the parent calix[4]pyrrole 1, it is clear that the introduction of eight electron-withdrawing groups do not change the geometries of the 1,3-alternate and cone conformers of 5-7 very much. ${ }^{8}$ In $\beta$-octachloro-calix[4]pyrrole 5, four pyrrole rings are more perpendicular to the mean plane consisting of the four $\mathrm{C}_{\text {meso }}$ carbons. It can be reflected by the enlarging of the dihedral angles $\varphi_{\mathrm{A}}-\varphi_{\mathrm{D}}$ to $74^{\circ}$ in 5a, Table $2 .{ }^{13}$ Meanwhile, they are only $70^{\circ}$ in $\mathbf{1 a}$. The weak Cl---H-N interaction might be one possible reason to interpret the geometrical change. The optimizations of these interactions make the pyrrole rings steeper. Differently, $\mathbf{5 b}$ is more flattened than $\mathbf{1 b}$. The dihedral angles $\varphi_{\mathrm{A}}-\varphi_{\mathrm{D}}$ in $\mathbf{5 b}$ are about $5^{\circ}$ less than those in $\mathbf{1 b}$. As expected, in $\beta$-octabromocalix[4]pyrrole 6, the geometry of 1,3-alternate 6a is very similar to 1a due to the weaker $\mathrm{Br}---\mathrm{H}-$ $\mathrm{N}$ interactions. The related dihedral angles $\varphi_{\mathrm{A}}-\varphi_{\mathrm{D}}$ only change by about $1^{\circ}$ comparing with structure 1a. Cone $\mathbf{6 b}$ almost retains the geometrical feature of $\mathbf{5 b}$. The displacement of $\mathrm{Br}$ groups with very strong electron-withdrawing groups $\mathrm{CN}$ at the $\beta$-position further tilts the four pyrrole rings up in the 1,3-alternate conformation 7a. It can be clearly observed from the $10^{\circ}$ increase of the related dihedral angles $\varphi_{A}-\varphi_{D}$ with respect to the parent calix[4]pyrrole 1a. Moreover, it implies that the stronger CN---H-N attraction occurs in the 1,3-alternate structure 7a. Our previous studies on the conformational features of the parent calix[4]pyrrole ${ }^{8}$ indicated that increasing of the dipole moments of the pyrrole rings should make them more titled above the mean plane. However, like $\mathbf{5 b}$ and $\mathbf{6 b}, \mathbf{7 b}$ is also slightly more flattened than $\mathbf{1 b}$. Thus, we believe that the electrostatic repulsion between two adjacent $\beta$-substituted groups on two neighbouring pyrrole rings plays animportant role in determining the structural shape of the cone conformation besides the dipole-dipole or electrostatic repulsion among the four pyrrole rings. In the later part, we will give the detailed evidence in supporting this argument.

It was found earlier that the 1,3-alterrnate conformer is more stable than the cone conformer at each level of calculation. ${ }^{8}$ The energy difference between the 1,3-alternate and cone conformations for the parent system $(\mathrm{X}=\mathrm{H})$ calculated with the $\mathrm{BLYP} / 6-31+\mathrm{G}^{* *}$ method is about 16.0 and $11.4 \mathrm{kcal} / \mathrm{mol}$ in the gas phase and in $\mathrm{CH}_{2} \mathrm{Cl}_{2}$, respectively (Table 3). When electron-withdrawing substituents are introduced, the preference for the 1,3-alternate conformation is increased (Table 3). This is especially the case for the strong electronwithdrawing cyano group. Thus, the preference for the 1,3-alternate conformation is increased to about 26.7 and $18.0 \mathrm{kcal} / \mathrm{mol}$ in the gas phase and in $\mathrm{CH}_{2} \mathrm{Cl}_{2}$, respectively, for $\beta$-octacyanocalix[4]pyrrole 7 . 
Table 2. Typical dihedral angles $\varphi_{A}-\varphi_{D}\left({ }^{\circ}\right)$ of 1,3-alternate, cone conformers, and their fluoro anion complexes of parent calix[4]pyrrole 1 and its substituted analogues 5-7

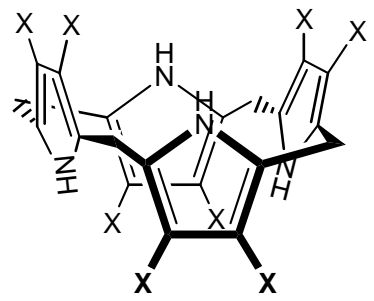

1,3-alternate

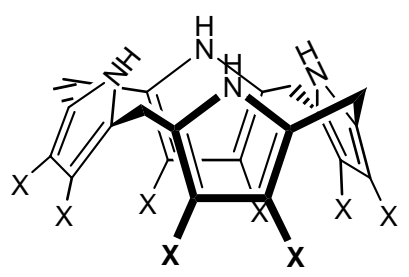

Cone

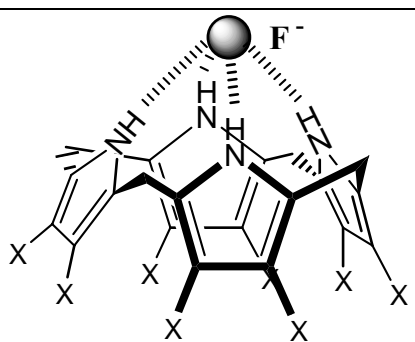

Cone-F

\begin{tabular}{cccc}
$\mathrm{X}$ & $\varphi_{\mathrm{A}=-} \varphi_{\mathrm{B}=} \varphi_{\mathrm{C}=-} \varphi_{\mathrm{D}}$ & $\varphi_{\mathrm{A}=} \varphi_{\mathrm{B}=} \varphi_{\mathrm{C}=} \varphi_{\mathrm{D}}$ & $\varphi_{\mathrm{A}=\varphi_{\mathrm{B}}=\varphi_{\mathrm{C}=} \varphi_{\mathrm{D}}}$ \\
\hline $\mathrm{H}(\mathbf{1})$ & 70 & 54 & 34 \\
$\mathrm{Cl}$ (5) & 74 & 49 & 37 \\
$\mathrm{Br}(\mathbf{6})$ & 71 & 48 & 37 \\
$\mathrm{CN}$ (7) & 80 & 51 & 36 \\
\hline
\end{tabular}

Table 3. Calculated energy difference $\left(\mathrm{E}_{\mathrm{cone}}-\mathrm{E}_{1,3-\text {-alternate, }}\right.$ in $\left.\mathrm{kcal} / \mathrm{mol}\right)$ between the 1,3-alternate and cone conformations of calix[4]pyrroles 1, 5-7 and their fluoro anion binding energies $\left(\Delta \mathrm{E}_{\text {binding }},=\mathrm{E}_{\text {cone-F}}{ }^{-}-\mathrm{E}_{1,3 \text {-alternate }}\right.$, in $\left.\mathrm{kcal} / \mathrm{mol}\right)$

\begin{tabular}{cccc}
\hline & $\mathrm{X}$ & $\mathrm{BLYP} / 6-31+\mathrm{G}^{* *}$ & $\mathrm{BLYP} / 6-31+\mathrm{G}^{* *}$ (sol.) \\
\hline $\mathrm{E}_{\text {cone }}-\mathrm{E}_{1,3 \text {-alternate }}$ & $\mathrm{H}$ & 16.0 & 11.4 \\
& $\mathrm{Cl}$ & 19.0 & 13.6 \\
& $\mathrm{Br}$ & 20.6 & 16.8 \\
& $\mathrm{CN}$ & 26.7 & 18.0 \\
$\Delta \mathrm{E}_{\text {binding }}$ & & & \\
& $\mathrm{H}$ & -66.6 & -23.1 \\
& $\mathrm{Cl}$ & -85.9 & -30.1 \\
& $\mathrm{Br}$ & -84.6 & -27.1 \\
& $\mathrm{CN}$ & -112.6 & -43.9 \\
\hline
\end{tabular}

\section{B. $\beta$-Substituent effects on calix[4]pyrrole- $F^{-}$complexes: structures and binding energies}

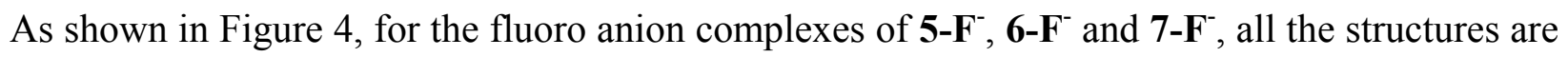
quite close to each other. The deviations of the dihedral angles are within $1^{\circ}$, Table 2 . The formation of the four anion-hydrogen bonds requires a significant ring flattening. As shown in Table 2, the dihedral angles $\varphi_{A}-\varphi_{D}$ are decreased by about $20^{\circ}$. Another structural property we should denote is the $2-3^{\circ}$ enlarging of the dihedral angles $\varphi_{A}-\varphi_{D}$ in complexes $\mathbf{5 - \mathbf { F } ^ { - }}, \mathbf{6 - \mathbf { F } ^ { - }}$ and $\mathbf{7 - \mathbf { F } ^ { - }}$ with respect to the fluoro anion complex of the parent calix[4]pyrrole $\mathbf{1}$.

The calculated fluoro anion-binding energies are collected in Table 3. Apparently, the electron-withdrawing groups at the $\beta$-positions significantly increase the fluoro anion binding 
energies with each level of calculations. In the gas phase, it is about $112.6 \mathrm{kcal} / \mathrm{mol}$ for $\mathrm{CN}$ groups even with the relatively large basis set $6-31+\mathrm{G}^{* *}$ basis set. As expected, the anion binding energy is reduced significantly in $\mathrm{CH}_{2} \mathrm{Cl}_{2}$ solution; but compound 7 still binds fluoro anion extremely tightly; quantitatively, the binding energy is increased by about $20 \mathrm{kcal} / \mathrm{mol}$ with respect to the parent calix[4]pyrrole 1. The anion binding energies of $\mathbf{5}$ and $\mathbf{6}$ are close to each other due to the similar and weak electron-withdrawing properties of $\mathrm{Cl}$ and $\mathrm{Br}$. They are only 7 and $4 \mathrm{kcal} / \mathrm{mol}$ larger than those of the parent calix[4]pyrrole (1), respectively.

Comparing with the experimental result that $\Delta \mathrm{G}_{\text {binding }}$ are about 5.8 and $6.0 \mathrm{kcal} / \mathrm{mol}$ for calix[4]pyrroles $\mathbf{2}$ and 3, the calculated anion binding energies, 23 and $27 \mathrm{kcal} / \mathrm{mol}$ for $\mathbf{1}$ and $\mathbf{6}$, are much larger. The neglect of binding entropy contribution and the effect of the mesooctamethyl groups in our calculations are possible causes of the discrepancy. However, the calculated binding energy ratio (1.17) between $\mathbf{1}$ and $\mathbf{6}$ is quite close to that observed in experiments (1.04) for the binding of fluoro anion. ${ }^{3}$

\section{III. $\beta$-Disubstituted dipyrromethane models}

From the calculated fluoro anion-binding energies of 1 and 5-7 (Table 3), it is clear that these binding energies are much less than those of the four individual pyrrole groups, that is, four times of the values of 10-F, 11-F, 12-F, and 14-F (Table 1). It implies that each N-H---F' hydrogen bond in 5-7 is much weaker than that in the pyrrole- $\mathrm{F}^{-}$model owing to the severe electrostatic repulsions among four conformationally rigid pyrroles. In addition, with the increasing of electron-withdrawing character of the $\beta$-substituent, this difference becomes larger.

Our previous work showed that the energy difference between anti and syn conformers in the dipyrromethane model is about 4.0 and $2.3 \mathrm{kcal} / \mathrm{mol}$ at the BLYP/6-31+G** level in the gas phase and in $\mathrm{CH}_{2} \mathrm{Cl}_{2}$ solution, respectively. ${ }^{8}$ Moreover, 4-fold of this difference would roughly reproduce the energy gap between 1,3-alternate and cone conformations. In order to estimate quantitatively the electrostatic repulsions between two adjacent pyrrole rings caused by the $\beta$ substituents, the $\beta$-disubstituted dipyrromethane models were calculated. Three models are considered; they are Model A, Model B and Model C (Table 4). In model A, four $\beta$-substituents are identical, $\mathrm{X}$ equals $\mathrm{Cl}, \mathrm{Br}$ or $\mathrm{CN}$. For model $\mathrm{B}$, substituents $\mathrm{R}_{2}$ and $\mathrm{R}_{3}$ are hydrogen while $\mathrm{R}_{1}$ and $\mathrm{R}_{4}$ are $\mathrm{Cl}, \mathrm{Br}$ or $\mathrm{CN}$. Contrast to model $\mathrm{B}$, substituents at $\mathrm{R}_{2}$ and $\mathrm{R}_{3}$ are $\mathrm{Cl}, \mathrm{Br}$ or $\mathrm{CN}$ and they are hydrogen at $R_{1}$ and $R_{4}$ in model $C$. The energies of these structures were evaluated by optimising the geometires with the constraint of the dihedral angles to the values in the corresponding 1,3-alternate and cone structures, respectively. All the calculated relative energies $\Delta \mathrm{E}$ between anti and syn orientations in model $\mathrm{A}$, model $\mathrm{B}$, and model $\mathrm{C}$ are listed in Table 4 . As expected, model A does fairly reproduce the 1/4 of energy difference between the 1,3-alternate and cone conformations (compare with Table 3). For example, when $\mathrm{X}=\mathrm{CN}$ in model $\mathrm{A}$, it is about 7.6 and $4.4 \mathrm{kcal} / \mathrm{mol}$ in the gas phase and in $\mathrm{CH}_{2} \mathrm{Cl}_{2}$ solution, respectively. Four times of these values $(30.4$ and $17.4 \mathrm{kcal} / \mathrm{mol})$ are close to those of the energy difference between the 1,3 - 
alternate and cone structures $(26.7$ and $18.0 \mathrm{kcal} / \mathrm{mol})$. They imply that the cone conformation is considerably destabilized by the $\beta$-substituents while the strength of $\mathrm{N}-\mathrm{H}$--- $\mathrm{Y}^{-}$hydrogen bond is

Table 4. Energy differences $\left(\Delta \mathrm{E}=\mathrm{E}_{\text {syn }}-\mathrm{E}_{\text {anti }}\right)$ between syn and anti orientations of model $\mathrm{A}$, model $\mathrm{B}$ and model $\mathrm{C}$ (in $\mathrm{kcal} / \mathrm{mol}$ )

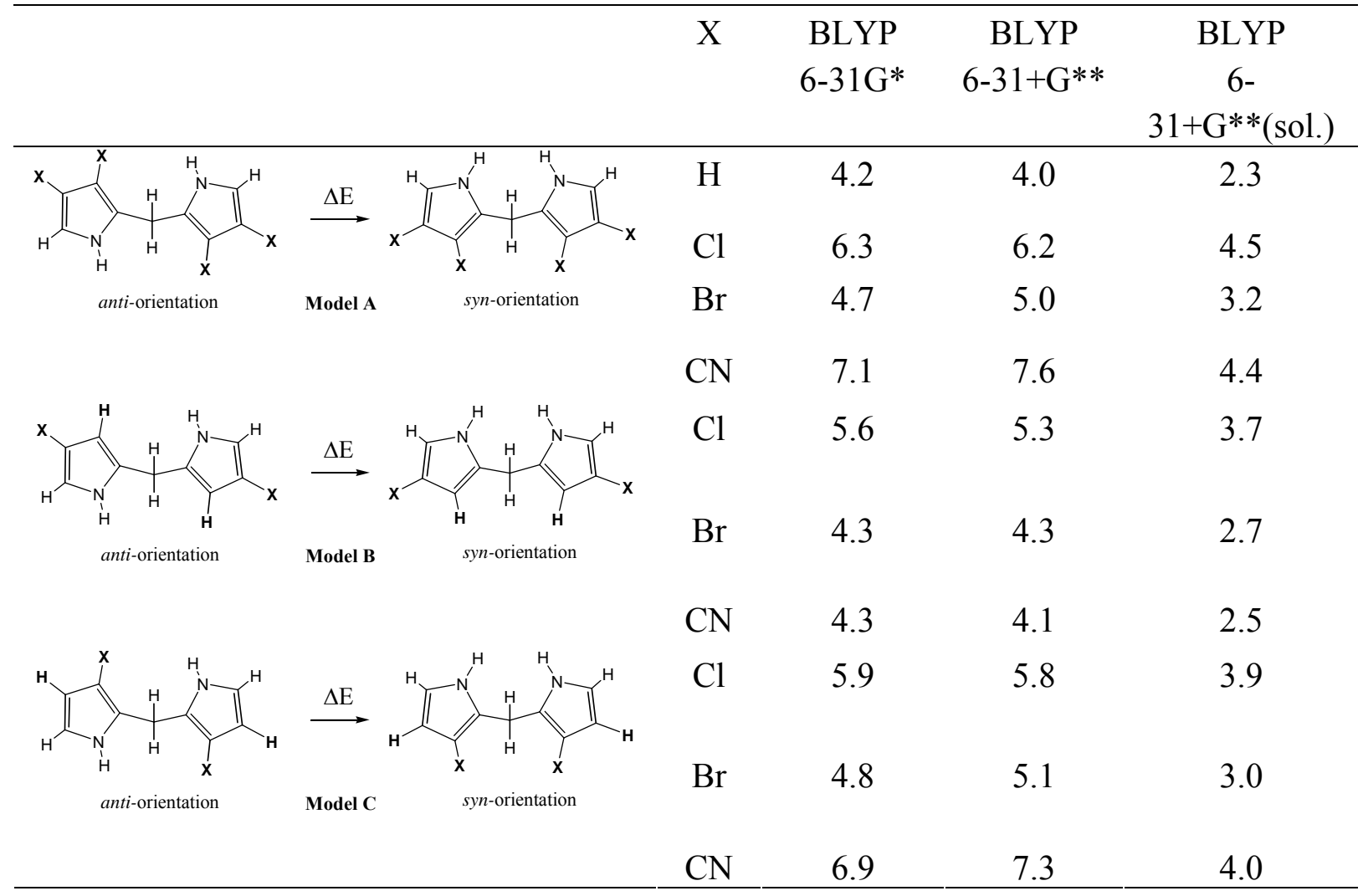

significantly enhanced by the substituents. It $\mathrm{s}$ also noted that the calculated energy differences in model $B$ are more close to the value of the parent case (model $A, X=H$ ), especially for the cases of $\mathrm{X}=\mathrm{Br}$ and $\mathrm{X}=\mathrm{CN}$. Further evidence in model $\mathrm{C}$ indicates that the calculated energy differences go back to the values of model $\mathrm{A}(\mathrm{X}=\mathrm{Cl}, \mathrm{Br}$, and $\mathrm{CN})$. All these reveal that the electrostatic repulsion between the two adjacent substituents destabilizes the syn orientation, and therefore, the cone conformation. Consistently, the substituent effect in model $\mathrm{A}(\mathrm{X}=\mathrm{Cl}, \mathrm{Br}$ or $\mathrm{CN}$ ) can be roughly considered as the summation of the substituent effects in model $\mathrm{B}$ and model C. For example, when $\mathrm{X}=\mathrm{CN}$ in $\mathrm{CH}_{2} \mathrm{Cl}_{2}$ solution, the effect of the four $\mathrm{CN}$ groups in Model $\mathrm{A}$ is about $2.1 \mathrm{kcal} / \mathrm{mol}$ respect to the parent case $(4.4-2.3 \mathrm{kcal} / \mathrm{mol})$; the effects of the two $\mathrm{CN}$ groups are about $0.2(2.5-2.3)$ and $1.7(4.0-2.3) \mathrm{kcal} / \mathrm{mol}$ in models B and C, respectively, a total effect of $1.9 \mathrm{kcal} / \mathrm{mol}$. 


\section{Conclusions}

Adjusting the electronic properties of $\beta$-substituents does significantly change the anion-binding ability of calix[4]pyrroles through electronic effect. From our calculated results with the BLYP/6-31+G** method in $\mathrm{CH}_{2} \mathrm{Cl}_{2}$ solution, the binding energies increase by about 7 and 4 $\mathrm{kcal} / \mathrm{mol}$ for $\mathrm{Cl}$ and $\mathrm{Br}$ substituents, respectively. When strong electron withdrawing $\mathrm{CN}$ groups are introduced, the binding energy is increased by about $18 \mathrm{kcal} / \mathrm{mol}$. However, the calculated results based on disubstituent-pyrrole and dipyrromethane models further indicate that those substitution patterns are not the most efficient because the $\beta$-substituents at the adjacent pyrrole rings have considerable repulsions when they are in syn-orientation in dipyrromethane model. This implies that the anion-binding ability is reduced by the electrostatic repulsion between the adjacent pyrrole rings because the cone structure, which is the conformation for anion-binding complex, is distabilized with respect to the global minimum, the 1,3-alternate structure. We believe that our results provide useful information for designing stronger and more efficient anion binding receptors.

\section{Supplementary Information}

All the DFT calculated total energies, relative energies and fluoride binding energies of $\beta$ substituted calix[4]pyrroles 1, 5-7, (See Page 122), and B3LYP/3-21G Cartesian coordinates of the structures of 1, 5-7 (See Page 123-125).

\section{Acknowledgments}

We thank the Research Grants Council of Hong Kong for financial support of the research.

\section{References and Notes}

1. Schmidtchen, F. P.; Berger, M. Chem. Rev. 1997, 97, 1609. (b) Lange III, L. G.; Riordan, J. F.; Vallèe, B. L. Biochemistry 1974, 13, 4361. (c) Schmidtchen, F. P. Nachr. Chem. Tech. Lab. 1988, 36, 8.

2. Selected books and chapters about anion-binding: (a) Supramolecular Chemistry of Anions, Bianchi, A.; Bowman-James, K.; Garcie-Espana, Eds.; Wiley-VCH: New York, 1997. (b) Lehn, J. M.; Atwood, J. L; Davies, J. E. D.; Macnicol, D. D.; Vögtle, F. Eds.; Comprehensive Supramolecular Chemistry: Molecular Recognition: Receptors for Molecular Guests, Pergamon Press: Oxford, 1996. Selected recent work on anion-binding: (c) Sessler, J. L.; Cyr, M.; Furata, H.; Kral, V.; Mody, T.; Morishima, T.; Shionoya, M.; 
Weghorn, S. Pure Appl. Chem. 1993, 65, 393. (d) Schmidchen, F. P.; Berger, M. Chem. Rev. 1997, 97, 1609. (e) Antonisse, M. M. G.; Reinhoudt, D. N. Chem. Commun. 1998, 443. (f) Atwood, J. L.; Holman, K. T.; Steed, J. W. Chem. Commun. 1996, 1401. (g) Beer, P. D. Chem. Commun. 1996, 689. (h) Lee, C. H.; Na, H. K.; Yoon, D. W.; Won, D. H.; Cho, W. S.; Lynch, V. M.; Shevchuk, S. V.; Sessler, J. L. J. Am. Chem. Soc. 2003, 125, 7301. (i) Sessler, J. L.; An, D. Q.; Cho, W. S.; Lynch, V. Angew. Chem. Int. Ed. 2003, 42, 2278. (j) Sessler, J. L.; Camiolo, S.; Gale, P. A. Coord. Chem. Rev. 2003, 240, 17.

3. Gale, P. A.; Sessler, J. L.; Král, V.; Lynch, V. J. Am. Chem. Soc. 1996, 118, 5140. (b) Allen, W. E.; Gale, A.; Brown, C. T.; Lynch, V. Sessler, J. L. J. Am. Chem. Soc. 1996, 118, 12471. (c) Sessler, J. L.; Andrievsky, A.; Gale, P. A.; Lynch, V. Angew. Chem. Int. Ed. Engl. 1996, 35, 2782. (d) Gale, A.; Sessler, J. L.; Allen, W. E.; Tvermoes, N. A.; Lynch, V. J. Chem. Soc., Chem. Commun. 1997, 665. (e) Gale, P. A.; Sessler, J. L.; Král, V. Chem. Commun. 1998, 1.

4. For a review, see Ungaro, R. et al. In Computational Approaches in Supramolecular Chemistry; Wipff, G., Ed.; NATO Series, Series C; Kluwer: Dordrecht, 1994; Vol. 371, p 277.

5. Grootenhuis, P. D. J.; Kollman, P. A.; Groenen, L. C.; Reinhout, D. N.; van Hummel, G. J.; Ugozzoli, F.; Andreetti, G. D. J. Am. Chem. Soc. 1990, 112, 4165. (b) Fischer, S.; Grootenhuis, P. D. J.; Groenen, L. C.; van Hoorn, W. P.; Veggel, F. C. J. M.; Reinhoudt, D. N.; Karplus, M. J. Am. Chem. Soc. 1995, 117, 1611. (c) Harada, T.; Shinkai, S. J. Chem. Soc., Perkin Trans. II 1995, 2231. (d) Wipff, G.; Engler, E.; Guilbaud, P.; Lauterbach, M.; Troxler, L.; Varnek, A. New J. Chem. 1996, 20, 403. (e) Wöhnert, J.; Brenn, J.; Stoldt, M.; Aleksiuk, O.; Grynszpan, F.; Thondorf, I.; Biali, S. E. J. Org. Chem. 1998, 63, 3866.

6. van Hoorn, W. P.; Jorgensen, W. L. J. Org. Chem. 1999, 64, 7439.

7. Blas, J. R.; Marquez, M.; Sessler, J. L.; Luque, F. J.; Orozco, M. J. Am. Chem. Soc. 2002, 124, 12796.

8. Wu, Y. -D., Wang, D. -F. and Sessler, J. L. J. Org. Chem. 2001, 66, 3739. (b) Wang, D. -F.; Wu, Y. -D. J. Theor. and Comput. Chem. 2004, 3, 51.

9. Frisch, M. J.; Trucks, G. W.; Schlegel, H. B.; Gill, P. M. W.; Johnson, B. G.; Robb, M. A.; Cheeseman, J. R.; Keith, T. A.; Peterson, G. A.; Montgomery, J. A.; Raghavachari, K.; AlLaham, M. A.; Zakrzewski, V. G.; Ortiz, J. V.; Foresman, J. B.; Cioslowski, J.; Stefanov, B. B.; Nanayakkara, A.; Challacombe, M.; Peng, C. Y.; Ayala, P. Y.; Chen, W.; Wong, M. W.; Andres, J. L.; Replogle, E. S.; Gomperts, R.; Martin, R. L.; Fox, D. J.; Binkley, J. S.; Defrees, D. J.; Baker, J.; Stewart, J. P.; Head-Gordon, M.; Gonzalez, C.; Pople, J. A. Gaussian 94 (Revision E. 2); Gaussian, Inc.: Pittsburgh, P. A., U.S.A., 1995.

10. Beck, A. D. Phys. Rev. A 1988, 38, 3098. (b) Lee, C.; Yang, W.; Parr, R. G. Phys. Rev. B 1988, 37, 785.

11. Hehre, W. J.; Radom, L.; Schleyer, P. v. R.; Pople, J. A. Ab Initio Molecular Orbital Theory; Wiley-Interscience: New York, 1986; pp 86-310. (b) Dunning, T. H., Jr.; Hay, P. J. In Modern Theoretical Chemistry; Schaefer, H. F., III, Ed.; Plenum: New York, 1977; Vol. 
1, Chapter 1. (c) Frisch, M. J.; Pople, J. A.; Del Bene, J. E. J. Chem. Phys. 1983, 78, 4063. (d) Del Bene, J. E.; Mette, H. D.; Frisch, M. J.; Luke, B. T.; Pople, J. A. J. Phys. Chem. 1983, 87, 3279. (e) Gao, J.; Garner, D. S.; Jorgensen, W. L. J. Am. Chem. Soc. 1986, 108, 4784. (f) Chen, J.; McAllister, M. A.; Lee, J. K.; Houk, K. N. J. Org. Chem. 1998, 63, 4611.

12. Wiberg, K. B.; Keith, T. A.; Frisch, M. J.; Murcko, M. J. Phys. Chem. 1995, 99, 9072. (b) Forseman, J. B.; Keith, T. A.; Wiberg, K. B.; Snoonian, J.; Frisch, M. J. J. Phys. Chem. 1996, 100, 16098. (c) Tomasi, J.; Bonaccorsi, R. Croat. Chem. Acta 1992, 12, 69.

13. As described in our previous work (ref 8), the typical dihedral angles $\varphi_{A}-\varphi_{D}$ are the angles between the pyrrole rings and the mean plane consisted by four meso-carbons, respectively. 